\title{
Root zone warming represses foliar diseases in tomato by inducing systemic immunity
}

\author{
Rupali Gupta ${ }^{1}$, Meirav Leibman-Markus ${ }^{1}$, Iftah Marash ${ }^{1}$, Neta Kovetz ${ }^{1}$, Dalia Rav-David ${ }^{1}$, \\ Yigal Elad ${ }^{1}$, and Maya Bar ${ }^{2}$ \\ ${ }^{1}$ Agricultural Research Organization Volcani Center \\ ${ }^{2} \mathrm{ARO}$
}

September 16, 2020

\begin{abstract}
Plants employ systemic induced resistance as part of their defense arsenal against pathogens. In recent years, the application of mild heating has been found to induce resistance against several pathogens. In the present study, we investigated the effect of root zone warming (RZW) in promoting tomato resistance against the necrotrophic fungus Botrytis cinerea (Bc), the hemibiotrophic bacterium Xanthomonas campestris pv. vesicatoria (Xcv) and the biotrophic fungus Oidium neolycopersici (On). We demonstrate that RZW enhanced tomato resistance to Bc, On and Xcv, through a process that is dependent on salicylic acid. RZW induced tomato immunity, resulting in increased defense gene expression, reactive oxygen species (ROS), and ethylene output when plants were challenged, even in the absence of pathogens. Overall, the results provide novel insights into the underlying mechanisms of warming induced immune responses against phytopathogens with different lifestyles in tomato.
\end{abstract}

\section{INTRODUCTION}

In agricultural environments, plants are often exposed to several stresses simultaneously. Changing climate suggests that combined biotic and abiotic stresses in agricultural settings may become more common, with opportunistic pathogens undergoing adaptations that will allow them to thrive under newly evolving conditions, while plants fight to maintain pathogen resistance capabilities in new ambient environments.

Reported thermo-tolerance mechanisms in plants can be diverse, with real-environment heat stress and adaptation being infinitely more varied than laboratory applied heat stresses in plant research. Four distinct thermo-tolerance mechanisms were proposed in Arabidopsis (Yeh et al., 2012), suggesting that plant responses to changing environmental temperatures can be highly complex.

Several reports have investigated different aspects of combinatorial plant stress, with varied conclusions (Saijo and Loo, 2020; Cappetta et al., 2020). While we are still at the beginning of understanding combinatorial stresses faced by plants in changing environments, several studies have concluded that transcriptional changes at the level of individual genes are highly variable and stress-specific (Zhang and Sonnewald, 2017). However, plants have a limited "tool-box" with which they must generate adequate stress responses, and indeed, many reports have also demonstrated that central metabolic and signaling responses to different individual and combined stresses can share commonalities (Zhang and Sonnewald, 2017). In this context, of note are the Heat-Shock Protein (HSP) family, which were found in several cases to not only be important in heat stress, but to also be involved in plant immunity (Kumar et al., 2009; Park and Seo, 2015; di Donato and Geisler, 2019; Yu et al., 2016). HSPs are molecular chaperones responsible for protein folding, assembly, translocation, and degradation under both steady state and stress conditions. In addition to abiotic stresses, HSPs were reported to serve chaperone functions in quality control of Pattern Recognition Receptors (PRRs) 
and intracellular R-proteins important in plant defense against pathogens (Nekrasov et al., 2009; Liu et al., 2004; Lee et al., 2009).

Combined heat-biotic stress has been reported to have varying results in terms of plant resistance/ susceptibility to pathogens. In many cases, abiotic stress pre-exposure can weaken disease resistance, while pathogen infections often enhance abiotic stress responses (Atkinson and Urwin, 2012). Heat-related suppression of disease resistance has been reported for viruses and bacteria, usually as a results of the hypersensitive response / R-gene being compromised at high temperatures (Janda et al., 2019; Prasch and Sonnewald, 2013; Zhu et al., 2010).

In other cases, abiotic stress was shown to enhance disease resistance. In heat treated rice leaves, the heating resulted in accumulation of superoxide radicals and resistance to rice blast (Aver'yanov et al., 1993). Disease resistance following high temperature exposure was also reported in wheat against a rust pathogen (Qayoum and Line, 1985) and in tobacco protoplasts against a tomato virus (Jones et al., 1990). More recent reports have shown that plant heating can serve to combat subsequent pathogenic processes, leading to improved disease outcomes with several pathogens. In sweet basil, the incidence of gray mold (Botrytis cinerea), white mold (Sclerotinia sclerotiorum) and downy mildew (Peronospora belbahrii) was found to be negatively correlated with high air and/or soil temperatures (Elad et al., 2017, 2016a). This disease amelioration effect was suggested to stem from host-induced mechanisms, rather than direct effects on the pathogens. In another report, soil polyethylene mulching was shown to reduce disease concomitantly with an increase in day-time soil temperatures (Shtienberg et al., 2010). Systemic disease resistance induced by heat was demonstrated in tomato and sweet basil, by exclusively heating the plant root zone, and observing disease resistance in the shoot/ canopy, which was measured to remain at ambient temperatures whilst the root zone was being heated (Elad et al., 2016a; Elad, 2018). Although the disease protectant effect achieved by root zone heating was demonstrated to be systemic, the molecular mechanisms driving this induced resistance were not examined.

In this work, we investigated the effectiveness of root-zone warming (RZW) as an inducer of disease resistance in tomato. We employ the term "warming" throughout this work, to distinguish the treatment applied from "heat-shock" protocols, in particular since the roots were only heated to $28^{\circ} \mathrm{C}$, a temperature which is not considered highly stressful in tomato breeding. We present evidence that RZW improves disease outcomes of the tomato fungal pathogens B. cinerea (Bc) and Oidium neolycopersici (On) and bacterial pathogenXanthomonas campestris pv. vesicatoria $(X c v)$. RZW treatments were sufficient to activate the tomato immune system, inducing defense gene expression and an increase in ethylene and reactive oxygen species (ROS) production upon challenge. Our results suggest that mechanisms which govern acclimation to changing ambient temperatures may be exploited in agriculture to promote disease resistance.

\section{RESULTS}

\subsection{Root zone warming enhances tomato resistance to $\mathrm{Bc}$ induced disease}

To determine the role of mild heat acclimation in tomato disease response, we examined the effect of warming tomato roots to $28^{\mathrm{O}} \mathrm{C}$ on pathogenesis of the necrotrophic fungus $B$. cinerea, the causative agent of gray mold disease. $B c$ infects more than 1400 plant species, infecting various organs of many important crops (Elad et al., 2016b). Tomato plants of wild type (WT) cv. Brigade, a susceptible tomato cultivar, and WT cv. M82, a less susceptible tomato cultivar, were grown at $21^{\mathrm{O}} \mathrm{C}$. Heat-induced disease reduction was previously reported in tomato for $B c$ in the Brigade cultivar (Elad, 2018). For experiments, treated plants were placed on a hot plate device which warmed the root zone to $28^{\circ} \mathrm{C}$, with constant temperature monitoring, on a "long-day" cycle, for 7 days. Further experimental information is provided in the materials section. Mock plants were mounted on a similar device which was not activated. After 7 days, plants were removed from the heating device, and infected with $B$. cinerea. Disease progression was monitored for 7 days. Throughout the experiment, the plant shoot remained at $21^{\mathrm{O}} \mathrm{C}$, as ensured by constant temperature measurement. RZW decreased the severity of $B c$ induced disease by about $60 \%$ in cv. Brigade (Figure 1a,b) and $40 \%$ in cv. M82 (Figure 1c,d). In both cultivars, disease was significantly lower at all time-points in the root-warmed plants 
when compared with the mock plants. The differences in the level of disease reduction are likely attributable to the initial difference in the level of disease susceptibility among the two cultivars.

Since warming the roots resulted in disease resistance in the shoots, which remained at $21^{\circ} \mathrm{C}$ during the entire experiment, the disease protectant effect generated by the treatments is systemic, as was previously suggested (Elad, 2018; Elad et al., 2016a).

Previous reports have indicated that there are several different types of heat acclimation in plants. The treatment we applied most resembles thermo-tolerance to moderate - high temperatures; TMHT (Yeh et al., 2012). To examine activation of the plant thermo-tolerance machinery as a result of the RZW we applied, we assayed the expression of classical heat shock genes in these plants in comparison with the mock plants. The heat-stress machinery was activated in the plants that received the RZW treatment (Figure 2), though it appears to be activated to a lesser degree than reported in the literature in connection with more classical "heat shock" experiments conducted, where typically, more extreme heat treatments are applied (Yang et al., 2016; Snyman and Cronjé, 2008; Fragkostefanakis et al., 2016). The induction levels of HSP and Hsf genes in tomato following our RZW treatment as compared with the induction achieved in a heat-shock experiment conducted in tomato (Fragkostefanakis et al., 2016), where higher induction values were observed (Supplemental Figure S1).

To examine the robustness and timing of disease protection in the plants which received the RZW treatments, we employed a second treatment protocol, where we applied the warming treatment for $48 \mathrm{~h}$ and subsequently infected the plants with $B c$ at different time-points after the warming treatment was applied. Three different time-points were selected, ranging from plants that received the heat treatment 5 days prior to $B c$ inoculation, all the way up to plants that received the heat treatment immediately prior to $B c$ inoculation. Plants which received the warming treatment 3 days prior to $B$ cinoculation, spending $72 \mathrm{~h}$ in $21^{\circ} \mathrm{C}$ recovery after the heat treatment and prior to $B c$ application, showed the greatest reduction in disease levels, in both Brigade (Figure 3a,b ) and M82 cultivars (Figure 3c,d ). This indicates that the acclimation processes occurring within the plant after RZW are amplified, in the context of immune system activation, after spending some time back in optimal temperatures.

\subsection{Root zone warming enhances tomato resistance to Xcv disease}

To determine whether RZW can induce resistance to additional classes of pathogens in tomato, as was previously reported in basil (Elad et al., 2017, 2016a), we examined the effect of RZW on pathogenesis of the hemibiotrophic pathogenic bacteria $X c v$, the causative agent of bacterial spot disease in many plant species (Moss et al., 2007). Wild type (WT) M82 tomato plants were treated with $48 \mathrm{~h} \mathrm{RZW} \mathrm{and} \mathrm{allowed}$ to recover for 3 days or 5 days prior to $X c v$ infection (Figure 4 ), and disease progression was measured using colony forming unit ( $\mathrm{CFU}$ ) count as described in the methodology section. Disease was assessed 3 days after pathogen inoculation. As we found for $B c$, RZW significantly decreased disease levels of $X c v$ in both Brigade (Figure 4a ) and M82 (Figure 4b ) cultivars. Once again, the disease reduction is due to systemic effects generated in the roots, which provide disease protection in the plant shoot.

\subsection{Root zone warming enhances tomato resistance to powdery mildew disease}

To determine whether RZW can induce tomato resistance to a biotrophic fungus, we examined the effect of RZW on pathogenesis of theOidium neolycopersici, which causes powdery mildew disease in tomato. Similar to the experiments detailed above for $B c$ and $X c v$, warming the root zone of tomato plants reduced the development of natural infection of tomato powdery mildew with the biotrophic fungus On (Figure 5 ) .

\subsection{Root zone warming induces tomato immunity}

Our results indicate that tomato pathogen-resistance is systemically modulated by RZW, as previously suggested (Elad et al., 2017, 2016a; Elad, 2018). To examine whether the decrease in fungal and bacterial disease following RZW is paired with increased plant defense in tomato, we tested known hallmarks of immune system activation: ethylene $\left(\mathrm{C}_{2} \mathrm{H}_{4}\right)$ and ROS production and defense gene expression. Warmed WT 
M82 plants exhibited an increase in ethylene production (Figure 6a), while the warmed plants of the Brigade cultivar did not exhibit a significant increase in wounding ethylene (Supplemental Figure S2 ), perhaps due to differences in the innate immunity mechanisms among these two cultivars as indeed, cv. Brigade plants are more susceptible to $B c$ than M82 plants.

To examine whether RZW augments defense responses elicited by known elicitors of plant defense, we employed the Xyn11 family xylanase Ethylene Inducing Xylanase (EIX), that induces Effector Triggered Immunity (ETI) in responsive cultivars (Sharon et al., 1993; Leibman-Markus et al., 2017; ; Bar and Avni, 2009), and the bacterial flagellin derived peptide flg-22, that is known to broadly induce immunity and ROS production (Felix et al., 1999; Segonzac and Zipfel, 2011). The combination of RZW and EIX or flg-22 induces immune responses- ethylene and ROS respectively, at greater levels than the elicitor alone in both cases (Figure 6a,b; Figure S2 ).

To analyze the alterations to tomato gene expression caused by RZW, we applied both 24 hour and 7 day RZW to M82 plants, and examined the expression of several known defense genes. Warming induced the expression of proteinase inhibitor 2 (PI-2 , Solyc03g020080), pathogenesis-related proteins (PR1a, Solyc01g106620) andPR-1b (Solyc00g174340), Pto-interacting 5 (Pti-5,Solyc02g077370), 1-aminocyclopropane1-carboxylate oxidase 1 (ACO-1, Solyc07g049530) and WRKY75 (Solyc05g015850) (Figure 7a ).

We also examined the effect of RZW on the expression of Pattern Recognition Receptors (PRRs) in the plant shoot. A recent report has demonstrated that increases in PRR expression correlate with enhanced immune outputs, being sufficient- along with cell damage- to mount strong localized immune responses to invading pathogens (Zhou et al., 2020). Figure 7b demonstrates that several PRRs are induced by RZW, indicating that PRR induction could underlie part of the induced resistance observed upon RZW.

We examined defense gene expression 24 hours after $B c$ inoculation, in both warmed and unwarmed plants (Figure 8 ). In most cases, $B c$ induced greater levels of the defense genes assayed when compared with RZW, consistent with the idea that the warming treatment causes immunity priming (Figure 8- compare black and pale-gray bars). For most assayed genes, RZW prior to B. cinereainoculation did not result in significant alterations to defense gene expression, when compared with $B c$ alone (Figure 8- black vs dark gray bars), suggesting that induced resistance by RZW decreases subsequent disease levels irrespective of its effect on gene expression. Positive correlations between B. cinerea disease levels and defense gene expression were reported previously (Meller-Harel et al., 2014; Mehari et al., 2015). The chosen genes are all hallmarks of pathogen responses (Martínez-Medina et al., 2013; Ament et al., 2004; Iberkleid et al., 2014; Cui et al., 2019; Thara et al., 1999; López-Ráez et al., 2010; Li et al., 2017; Harel et al., 2014). Interestingly, comparing $B$. cinerea induced gene expression with heat-shock induced gene expression in published datasets yields several defense related genes and transcription factors which are induced in both cases, and could be promising targets for future research (Supplemental Figure S3).

\subsection{Warming induced disease resistance is $S A$ dependent}

To examine the potential involvement of SA in warming- mediated resistance against $B c$, we conducted pathogenesis assays in an SA deficient transgenic line. Root zone warming was applied for 48h followed by a 3 day recovery period. Following $B c$ inoculation, disease severity was assessed for 5 days. Figure 9 shows that the warming treatment did not protect the SA deficient NahGtransgenic plants (Brading et al., 2000) from $B c$ induced disease, indicating that the SA signaling pathway is required for induction of warming mediated resistance against $B c . B c$ disease levels in the mock $N a h G$ plants were decreased as expected (Ciardi et al., 2000; O'Donnell et al., 2001, 2003) (Figure 8). Similar results were achieved in SA deficient $N a h G$ transgenic plants withO. neolycopersici (Supplemental Figure S4 ).

\section{DISCUSSION}

With growing evidence that root zone warming induces systemic disease resistance in tomato, this work aimed to decipher the molecular mechanisms underlying this phenomenon. We have shown that RZW activates immunity in tomato, increasing the expression of defense genes and PRRs, along with the induction of 
ethylene and ROS. This activated immune system, in turn, results in systemic disease resistance to both biotrophic and necrotrophic pathogens, indicating that it is a mechanism common to several biotic signaling pathways.

Interestingly, we found that warming-induced immunity relies on the SA signaling pathway. Heating treatments were previously shown to affect SA signaling (Arofatullah et al., 2018; Sato et al., 2003; Widiastuti et al., 2013; Snyman and Cronjé, 2008).

Our work indicates that root zone warming treatments are most effective in promoting disease resistance to $B c$ after a short recovery period (Figure 3), though, interestingly, in the case of Xcvdisease resistance, different recovery periods had similar effects (Figure 4). Perhaps this is due to the different nature of the pathogens, with root-zone warming initially priming SA mediated pathways (Figure 9), which are also required for $X c v$ resistance (Xu et al., 2018), while the effect on attributes required for necrotrophic pathogen resistance require a longer period of "acclimation".

Evidences of commonalities between heat stress and biotic stress signaling pathways have been previously reported (Zhang and Sonnewald, 2017; Suzuki and Katano, 2018; Jacob et al., 2017). In particular, HSPs have been demonstrated to be involved in the response to both heat and biotic stressors (di Donato and Geisler, 2019; Yu et al., 2016). Over-expression of heat shock proteins in plants has been proposed as one of the potential strategies to combat heat stress. HSPs function as molecular chaperons, are involved in correct protein folding, assembly, translocation, degradation and they also provide stability to integral proteins and cell membranes under heat stress (Boston et al., 1996). HSPs reportedly serve chaperone functions in quality control of plant defense PRRs (Nekrasov et al., 2009; Lee et al., 2009). Interestingly, we found that several PRRs were induced by the same root zone warming treatment that was sufficient to promote pathogen resistance (Figure 6b), supporting the notion that PRR alterations in response to wounding or biotic cues can be sufficient to activate plant defense (Zhou et al., 2020; Saijo et al., 2018).

Low-level induction of HSPs concurrent with induced resistance to $B c, O n$ and $X c v$ suggest that the same mechanisms which exert abiotic stress tolerance also activate immune mechanisms in tomato, as was previously suggested (di Donato and Geisler, 2019; Yu et al., 2016; Zhang and Sonnewald, 2017). The activation of HSPs by pathogenic processes demonstrates the common signaling pathways which can underlie the plants' response to several different types of stresses, which, ideally, would be those manipulated in order to generate resistance and agriculturally desirable cultivars in the face of combinatorial stress created by climate change. Of note is that, similar to what we found for root-zone warming induced immunity to $B c$, acquired thermo-tolerance also requires a short acclimation period, after which plants become more resistant to subsequent heat application (Baniwal et al., 2004; Charng et al., 2007) perhaps indicating that conserved machinery may be important in both types of stress.

Interestingly, transgenic tomato plants expressing the Arabidopsis NPR-I gene developed enhanced heat tolerance in addition to varying levels of resistance against several tomato pathogens, testifying to the connection between heat tolerance and biotic resistance (Lin et al., 2004). This also supports our results demonstrating that warming-induced resistance relies on an intact SA pathway (Figure 9). In addition to HSPs, ROS scavenging abilities were reported to be essential in both heat and biotic resistance (Piterková et al., 2013; Vallélian-Bindschedler et al., 1998; Suzuki and Katano, 2018), and thus, ROS homeostasis may be another underlying common mechanism that might explain why increased heat tolerance also affords induced immunity and pathogen resistance. Our results demonstrate that ROS inducing mechanisms are affected by root zone warming (Figure 6b).

The use of pesticides and chemicals in agriculture is hazardous to human health and lacks environmental sustainability. From a farmer's perspective, any improvement that reduces the cost of chemical application is desirable. Heat induced systemic disease resistance represents an attractive strategy to aid in combatting pathogens, given its economical and environmentally friendly nature. Further, when combining different priming agents to potentiate plant immunity, our results indicate that warming treatments could best be combined with JA-pathway ISR inducers, to achieve combined effects by potentiating different immunity 
pathways simultaneously. Our results suggest that mechanisms which govern acclimation to changing ambient temperatures may be exploited in agriculture to promote disease resistance. Further research will elucidate whether a potential use of root zone warming as an eco-friendly disease control agent in agricultural systems is feasible.

\section{Acknowledgements}

The authors would like to thank Guido Sessa for providing the Xcvstrain. MB thanks members of the Bar group for continuous discussion and support.

\section{MATERIALS AND METHODS4.1 Plant materials and growth conditions}

Seeds of the Solanum lycopersicum cultivars Brigade, M82 and Moneymaker (MM), as well as the decreased SA transgenic lineNahG, were used throughout the study. Tomato plants were grown from seeds in soil (Green Mix; Even-Ari, Ashdod, Israel) in a growth chamber at 60-70\% relative humidity and under a longday photoperiod consisting of a 16-h light followed by an 8-h dark period, at $24 \mathrm{degC}$.

\subsection{Root zone warming treatments}

Flat heating plates were placed on a growth chamber table and alternately operated for 15 minutes/ and ceased heating for 15 minutes for 10 hours/day. No heating was applied for the subsequent $14 \mathrm{~h}$. Each cycle of RZW was $24 \mathrm{~h}$ composed of $10 \mathrm{~h}$ with intermittent warming, and $14 \mathrm{~h}$ without. Disposable aluminum trays $(30 \mathrm{X} 40 \mathrm{~cm})$ containing $7-10 \mathrm{~mm}$ height of tap water were placed over the heaters and $800 \mathrm{ml}$ pots with six week old tomato plants were placed in the aluminum trays. The plants were fertilized with slow release fertilizer (1 g each, Osmocote, Everris International BV, Heerlen, The Netherlands) containing $\mathrm{N}$ (18\%), $\mathrm{P}_{2} \mathrm{O}_{5}(9 \%), \mathrm{K}_{2} \mathrm{O}(10 \%), \mathrm{MgO}(2 \%), \mathrm{Fe}(0.3 \%), \mathrm{Mn}(0.04 \%), \mathrm{Cu}(0.037 \%), \mathrm{Zn}(0 / 011 \%), \mathrm{B}(0.1 \%)$, Mo $(0.015 \%)$ and water was added daily to the pots. Temperature at $5 \mathrm{~cm}$ depth of the mock and treated pots reached $21+-1$ and $28+-1 \mathrm{oC}$ during the warming period while the canopy temperatures were $18-21 \mathrm{oC}$ during the entire experiment. This experimental design aimed at mimicking real agricultural conditions, where natural daytime soil heating in different settings can result in root zone warming while the plant canopy remains at lower temperatures (Elad et al., 2016a). Incubation took place in an illuminated, air conditioned growth chamber with $21+-1 \mathrm{oC}$ and 2200 Lux light intensity, $12 \mathrm{~h}$ daylight.

\subsection{B. cinerea inoculation and disease evaluation}

B. cinerea (isolate BcI16) was cultured on Potato Dextrose Agar (PDA) in Petri dishes incubated at 22degC. Conidia were harvested from 10- to 14-day-old cultures by agitating $1 \mathrm{~cm}^{2}$ of agar bearing mycelium and conidia in a glass tube with tap water. The suspension was then filtered through cheesecloth. The concentration of conidia was determined using a haemocytometer under a light microscope, and adjusted to $10^{6}$ cells $\mathrm{mL}^{-1} .0 .1 \%$ glucose and $0.1 \% \mathrm{~K}_{2} \mathrm{HPO}_{4}$ were added to the final conidial suspension. Whole plants were inoculated with this conidial suspension. The severity of the resulting necrotic lesions was determined as the percentage of necrotic area, according to the 0-100\% scale described previously (Meller Harel et al., 2014). The level of disease was evaluated every 2-3 days for a period of 10 days. Alternatively, $3 \mathrm{~mm}$ diameter discs of 3 day-old PDA cultured B. cinerea were placed on each of 4 leaflets of leaf number 5 and rot area was measured 3 to 5 days after inoculation.

\subsection{X. campestris inoculation and disease evaluation}

$X$. campestris pv. vesicatoria strain 85-10 (Xcv) was used for bacterial infection analysis. Pathogenicity assays were performed according to (O'Donnell et al., 2001). Briefly, bacterial cultures were grown in Luria Bertani (LB) medium containing $100 \mathrm{mg} \mathrm{L}^{-1}$ of rifampicin and $300 \mathrm{mg} \mathrm{L}^{-1}$ of streptomycin, overnight at 28degC. Log phase bacterial cultures were harvested and re-suspended in $10 \mathrm{mM} \mathrm{MgCl}_{2}$ at a final concentration of $10^{5} \mathrm{CFU} \mathrm{mL}-1\left(\mathrm{OD}_{600}=0.0002\right)$. The fourth leaf of 5-week-old tomato plants were vacuum immersed with the bacterial suspensions. Three days after infiltration, three leaf discs of $0.9 \mathrm{~cm}$ diameter were sampled from at least four plants from each genotype and ground in $1 \mathrm{ml}$ of $10 \mathrm{mM} \mathrm{MgCl} 2$. Bacterial pathogen 
CFU were determined by plating and counting the resulting colonies (Lund et al., 1998). Negative controls consisted of $10 \mathrm{mM} \mathrm{MgCl}_{2}$ without pathogen inoculation. Plants were subjected to $2 \mathrm{RZW}$ cycles followed by three recovery days before they were infected by $X c v$ as mentioned above.

\subsection{O. neolycopersici inoculation and disease evaluation}

Plants were grown in the vicinity of $O$. neolycopersici infested plants in a greenhouse compartment. The naturally infected plants were subjected to 2 RZW cycles followed by three days recovery. The severity of the disease symptoms on leaves was evaluated according to a $0-100 \%$ scale where $0=$ symptomless leaves and $100=$ fully covered leaves with mycelium and conidia of the fungus (Jacob et al., 2008).

\subsection{RNA extraction and qRT-PCR}

For qRT-PCR analyses, total RNA was extracted using Tri reagent (Sigma-Aldrich) according to the manufacturer's instructions, and 3ug of RNA was converted to first strand cDNA using reverse transcriptase (Promega, United States) and oligo-d(T) primers according to the manufacturer's instructions. qRT-PCR was performed according to the Power SYBR Green Master Mix protocol (Life Technologies, Thermo Fisher, United States), using a Rotor-Gene Q machine (Qiagen). Supplemental Table 1 lists the specific primers used in this study. The housekeeping gene coding for ribosomal protein RPL8 (accession number Solyc10g006580) was used for the normalization of gene expression in all qRT-PCR analyses. Relative expression quantification was calculated using copy number method for gene expression experiments (D'haene et al., 2010).

\subsection{Ethylene measurement}

Ethylene production was measured as previously described (Leibman-Markus et al., 2017). Leaf discs 0.9 $\mathrm{cm}$ in diameter were harvested from indicated genotypes, and average weight was measured for each plant. Discs were washed in water for 1-2 h. Every six discs were sealed in a $10 \mathrm{~mL}$ flask containing $1 \mathrm{ml}$ assay medium (with or without $1 \mu \mathrm{g} \mathrm{ml}{ }^{-1}$ EIX) for $4 \mathrm{~h}$ at room temperature. Ethylene production was measured by gas chromatography (Varian 3350, Varian, California, USA).

\subsection{Oxidative burst- ROS measurement}

ROS measurement as previously described (Leibman-Markus et al., 2017). Leaf disks of $0.5 \mathrm{~cm}$ in diameter were harvested from leaves 4-5 of 5-6 week old M82 Mock and root-zone warmed tomato plants. Disks were floated in a white 96-well plate (SPL Life Sciences, Korea) containing $250 \mu$ l distilled water for 4-6 h at room temperature. After washing, water was removed and a ROS measurement reaction containing $1 \mathrm{mM}$ flg-22 or water was added. Light emission was measured for 30 minutes using a luminometer (Tecan Spark, Switzerland). Each experiment was repeated four times with 13 technical replicates $\left(\mathrm{N}_{\text {total }}=52\right)$.

\subsection{Data analysis}

All experimental data is presented as average \pm SEM. Differences between two groups were analyzed for statistical significance using a two-tailed t-test. Differences among three groups or more were analyzed for statistical significance with a one-way ANOVA. Regular ANOVA was used for groups with equal variances, and Welch's ANOVA for groups with unequal variances. When a significant result for a group in an ANOVA was returned, significance in differences between the means of different samples in the group were assessed using a post-hoc test. The Tukey test was employed for samples with equal variances when the mean of each sample was compared to the mean of every other sample. The Bonferroni test was employed for samples with equal variances when the mean of each sample was compared to the mean of a control sample. The Dunnett test was employed for samples with unequal variances. All statistical analyses were conducted using Prism8 $8^{\mathrm{TM}}$.

\section{Supplemental material}

\section{Supplemental Figures}

Supplemental Figure 1: Root zone warming induces heat-shock gene expression to lower levels than heatshock treatment. 
Supplemental Figure 2: Root zone warming induces ethylene production in the Brigade cultivar.

Supplemental Figure 3: Genes commonly induced by both Heat-shock andBotrytis cinerea infection.

Supplemental Figure 4: Root zone warming induced powdery mildew (O. neolycopersici ) resistance is SA dependent.

\section{Supplemental Table}

Supplemental table 1: qPCR primers used in this work.

\section{Bibliography}

Ament, K., Kant, M.R., Sabelis, M.W., Haring, M.A., and Schuurink, R.C. (2004). Jasmonic acid is a key regulator of spider mite-induced volatile terpenoid and methyl salicylate emission in tomato. Plant physiology 135 : 2025-37.

Arofatullah, N.A., Hasegawa, M., Tanabata, S., Ogiwara, I., and Sato, T. (2018). Heat ShockInduced Resistance Against Pseudomonas syringae pv. tomato (Okabe) Young et al. via Heat Shock Transcription Factors in Tomato. Agronomy $9: 2$.

Atkinson, N. and Urwin, P. (2012). The Interaction of Plant Biotic and Abiotic Stresses: From Genes to the Field. Journal of experimental botany 63 .

Aver'yanov, A.A., Lapikova, V.P., and Djawakhia, V.G. (1993). Active oxygen mediates heat-induced resistance of rice plant to blast disease. Plant Science 92 : 27-34.

Baniwal, S.K. et al. (2004). Heat stress response in plants: A complex game with chaperones and more than twenty heat stress transcription factors. Journal of Biosciences 29 : 471-487.

Bar, M. and Avni, A. (2009). EHD2 inhibits ligand-induced endocytosis and signaling of the leucine-rich repeat receptor-like protein LeEix2. The Plant Journal 59 : 600-611.

Boston, R.S., Viitanen, P. V., and Vierling, E. (1996). Molecular chaperones and protein folding in plants. Plant Molecular Biology 32 : 191-222.

Brading, P.A., Hammond-Kosack, K.E., Parr, A., and Jones, J.D.G. (2000). Salicylic acid is not required for $C f-2$ - and $C f-9$-dependent resistance of tomato to Cladosporium fulvum. The Plant Journal 23 : 305-318.

Cappetta, E., Andolfo, G., Di Matteo, A., and Ercolano, M.R.(2020). Empowering crop resilience to environmental multiple stress through the modulation of key response components. Journal of Plant Physiology $246-247$.

Charng, Y.Y., Liu, H.C., Liu, N.Y., Chi, W.T., Wang, C.N., Chang, S.H., and Wang, T.T. (2007). A heat-inducible transcription factor, HsfA2, is required for extension of acquired thermotolerance in Arabidopsis. Plant Physiology 143 : 251-262.

Ciardi, J.A., Tieman, D.M., Lund, S.T., Jones, J.B., Stall, R.E., and Klee, H.J. (2000). Response to Xanthomonas campestris pv. vesicatoria in tomato involves regulation of ethylene receptor gene expression. Plant physiology 123 : 81-92.

Cui, H., Sun, Y., Zhao, Z., and Zhang, Y. (2019). The Combined Effect of Elevated O3 Levels and TYLCV Infection Increases the Fitness of Bemisia tabaci Mediterranean on Tomato Plants. Environmental Entomology.

D'haene, B., Vandesompele, J., and Hellemans, J. (2010). Accurate and objective copy number profiling using real-time quantitative PCR. Methods 50 : 262-270.

di Donato, M. and Geisler, M. (2019). HSP90 and co-chaperones: a multitaskers' view on plant hormone biology. FEBS Letters593 : 1415-1430. 
Elad, Y. (2018). Disease management: Disease suppression by cultural means and through biocontrol. Acta Horticulturae 1207 : 105-113.

Elad, Y., Omer, C., Nisan, Z., Harari, D., Goren, H., Adler, U., Silverman, D., and Biton, S. (2016a). Passive heat treatment of sweet basil crops suppresses Peronospora belbahrii downy mildew. Annals of Applied Biology 168 : 373-389.

Elad, Y., Pertot, I., Cotes Prado, A.M., and Stewart, A.(2016b). Plant Hosts of Botrytis spp. In Botrytis - the Fungus, the Pathogen and its Management in Agricultural Systems (Springer International Publishing: Cham), pp. 413-486.

Elad, Y., Rav David, D., Israeli, L., and Fogel, M. (2017). Passive heat treatment of sweet basil crops suppresses white mould and grey mould. Plant Pathology 66 : 105-114.

Elbaz, M., Avni, A., and Weil, M. (2002). Constitutive caspase-like machinery executes programmed cell death in plant cells. Cell Death and Differentiation 9 : 726-733.

Felix, G., Duran, J.D., Volko, S., and Boller, T. (1999). Plants have a sensitive perception system for the most conserved domain of bacterial flagellin. Plant Journal $18: 265-276$.

Fragkostefanakis, S., Mesihovic, A., Simm, S., Paupière, M.J., Hu, Y., Paul, P., Mishra, S.K., Tschiersch, B., Theres, K., Bovy, A., Schleiff, E., and Scharf, K.-D. (2016). HsfA2 Controls the Activity of Developmentally and Stress-Regulated Heat Stress Protection Mechanisms in Tomato Male Reproductive Tissues. Plant Physiology 170 : 2461-2477.

Harel, Y.M., Mehari, Z.H., Rav-David, D., and Elad, Y. (2014). Systemic Resistance to Gray Mold Induced in Tomato by Benzothiadiazole and Trichoderma harzianum T39. Phytopathology 104 : 150-157.

Iberkleid, I., Ozalvo, R., Feldman, L., Elbaz, M., Patricia, B., and Horowitz, S.B. (2014). Responses of Tomato Genotypes to Avirulent and Mi -Virulent Meloidogyne javanica Isolates Occurring in Israel. Phytopathology 104 : 484-496.

Jacob, D., Rav David, D., Sztjenberg, A., and Elad, Y. (2008). Conditions for Development of Powdery Mildew of Tomato Caused by Oidium neolycopersici. Phytopathology 98 : 270-281.

Jacob, P., Hirt, H., and Bendahmane, A. (2017). The heat-shock protein/chaperone network and multiple stress resistance. Plant Biotechnology Journal 15 : 405-414.

Janda, M., Lamparová, L., Zubíková, A., Burketová, L., Martinec, J., and Krčková, Z. (2019). Temporary heat stress suppresses PAMP-triggered immunity and resistance to bacteria in Arabidopsis thaliana. Molecular Plant Pathology 20 : 1005-1012.

Jones, R., Jackson, A., and Morris, T. (1990). Defective-interfering RNAs and Elevated Temperatures Inhibit Replication of Tomato Bushy Stunt Virus in Inoculated Protoplasts. Virology 176 .

Kumar, M., Busch, W., Birke, H., Kemmerling, B., Nürnberger, T., and Schöff, F. (2009). Heat shock factors HsfB1 and HsfB2b are involved in the regulation of Pdf1.2 expression and pathogen resistance in Arabidopsis. Molecular Plant 2 : 152-165.

Lee, H., Gal, S., Newman, T., Raikhel, N., Roux, M., Chinchilla, D., Zipfel, C., and Jones, J.D.G. (2009). The Arabidopsis endoplasmic reticulum retention receptor functions in yeast. PNAS 90 : 11433-11437.

Leibman-Markus, M., Schuster, S., and Avni, A. (2017a). LeEIX2 Interactors' Analysis and EIXMediated Responses Measurement. In Methods in molecular biology (Clifton, N.J.), pp. 167-172.

Leibman-Markus, M., Schuster, S., and Avni, A. (2017b). LeEIX2 Interactors' Analysis and EIXMediated Responses Measurement. In Plant Pattern Recognition Receptors: Methods and Protocols, L. Shan and P. He, eds (Springer New York: New York, NY), pp. 167-172. 
Li, Y., Qin, L., Zhao, J., Muhammad, T., Cao, H., Li, H., Zhang, Y., and Liang, Y. (2017). SIMAPK3 enhances tolerance to tomato yellow leaf curl virus (TYLCV) by regulating salicylic acid and jasmonic acid signaling in tomato (Solanum lycopersicum). PLOS ONE 12 : e0172466.

Lin, W., Lu, C., Wu, J., Cheng, M., Lin, Y., Yang, N., Black, L., Green, S., Wang, J., and Cheng, C. (2004). Transgenic Tomato Plants Expressing the Arabidopsis NPR1 Gene Display Enhanced Resistance to a Spectrum of Fungal and Bacterial Diseases. Transgenic research13 .

Liu, Y., Burch-Smith, T., Schiff, M., Feng, S., and Dinesh-Kumar, S.P. (2004). Molecular Chaperone Hsp90 Associates with Resistance Protein N and Its Signaling Proteins SGT1 and Rar1 to Modulate an Innate Immune Response in Plants. Journal of Biological Chemistry 279 : 2101-2108.

López-Ráez, J.A., Verhage, A., Fernández, I., García, J.M., Azcón-Aguilar, C., Flors, V., and Pozo, M.J. (2010). Hormonal and transcriptional profiles highlight common and differential host responses to arbuscular mycorrhizal fungi and the regulation of the oxylipin pathway. Journal of Experimental Botany 61 : 2589-2601.

Lund, S.T., Stall, R.E., and Klee, H.J. (1998). Ethylene regulates the susceptible response to pathogen infection in tomato. Plant Cell $10: 371-382$.

Martínez-Medina, A., Fernández, I., Sánchez-Guzmán, M.J., Jung, S.C., Pascual, J.A., and Pozo, M.J. (2013). Deciphering the hormonal signalling network behind the systemic resistance induced by Trichoderma harzianum in tomato. Frontiers in Plant Science $4: 206$.

Mehari, Z.H., Elad, Y., Rav-David, D., Graber, E.R., and Meller Harel, Y. (2015). Induced systemic resistance in tomato (Solanum lycopersicum) against Botrytis cinerea by biochar amendment involves jasmonic acid signaling. Plant and Soil 395 : 31-44.

Moss, W.P., Byrne, J.M., Campbell, H.L., Ji, P., Bonas, U., Jones, J.B., and Wilson, M. (2007). Biological control of bacterial spot of tomato using hrp mutants of Xanthomonas campestris pv. vesicatoria. Biological Control 41 : 199-206.

Nekrasov, V. et al. (2009). Control of the Pattern-Recognition Receptor EFR by an ER Protein Complex in Plant Immunity. The EMBO journal 28 .

O'Donnell, P.J., Jones, J.B., Antoine, F.R., Ciardi, J., and Klee, H.J. (2001). Ethylene-dependent salicylic acid regulates an expanded cell death response to a plant pathogen. The Plant Journal25 : 315-323.

O’Donnell, P.J., Schmelz, E., Block, A., Miersch, O., Wasternack, C., Jones, J.B., and Klee, H.J. (2003). Multiple Hormones Act Sequentially to Mediate a Susceptible Tomato Pathogen Defense Response. Plant Physiology 133 : 1181.

Park, C.-J. and Seo, Y.-S. (2015). Heat Shock Proteins: A Review of the Molecular Chaperones for Plant Immunity. The Plant Pathology Journal 31 .

Piterková, J., Luhová, L., Mieslerová, B., Lebeda, A., and Petřivalský, M. (2013). Nitric oxide and reactive oxygen species regulate the accumulation of heat shock proteins in tomato leaves in response to heat shock and pathogen infection. Plant Science207 : 57-65.

Prasch, C.M. and Sonnewald, U. (2013). Simultaneous application of heat, drought, and virus to Arabidopsis plants reveals significant shifts in signaling networks. Plant physiology 162 : 1849-66.

Qayoum, A. and Line, R. (1985). High-Temperature, Adult-Plant Resistance to Stripe Rust of Wheat. Phytopathology $75: 1121$.

Ron, M., Kantety, R., Martin, G.B., Avidan, N., Eshed, Y., Zamir, D., and Avni, A. (2000). High-resolution linkage analysis and physical characterization of the EIX-responding locus in tomato. Theor. Appl. Genet. 100 : 184-189. 
Saijo, Y. and Loo, E.P. iian (2020). Plant immunity in signal integration between biotic and abiotic stress responses. New Phytologist225 : 87-104.

Saijo, Y., Loo, E.P. iian, and Yasuda, S. (2018). Pattern recognition receptors and signaling in plantmicrobe interactions. Plant Journal 93 : 592-613.

Sato, T., Kubo, M., and Watanabe, S. (2003). Heat shock induces a systemic acquired resistance (SAR)-related gene via salicylic acid accumulation in cucumber (Cucumis sativus L.). Japanese Journal of Tropical Agriculture $47: 77-82$.

Segonzac, C. and Zipfel, C. (2011). Activation of plant pattern-recognition receptors by bacteria. Current Opinion in Microbiology $14: 54-61$.

Sharon, A., Fuchs, Y., and Anderson, J.D. (1993). The Elicitation of Ethylene Biosynthesis by a Trichoderma Xylanase Is Not Related to the Cell Wall Degradation Activity of the Enzyme. Plant physiology 102 : $1325-1329$.

Shtienberg, D., Elad, Y., Bornstein, M., Ziv, G., Grava, A., and Cohen, S. (2010). Polyethylene mulch modifies greenhouse microclimate and reduces infection of Phytophthora infestans in tomato and Pseudoperonospora cubensis in cucumber. Phytopathology 100 : 97-104.

Snyman, M. and Cronjé, M.J. (2008). Modulation of heat shock factors accompanies salicylic acidmediated potentiation of Hsp70 in tomato seedlings. Journal of Experimental Botany 59 : 2125-2132.

Suzuki, N. and Katano, K. (2018). Coordination between ROS regulatory systems and other pathways under heat stress and pathogen attack. Frontiers in Plant Science $\mathbf{9}$.

Thara, V.K., Tang, X., Gu, Y.Q., Martin, G.B., and Zhou, J.-M.(1999). Pseudomonas syringae pv tomato induces the expression of tomato EREBP-like genes Pti4 and Pti5 independent of ethylene, salicylate and jasmonate. The Plant Journal 20 : 475-483.

Vallélian-Bindschedler, L., Schweizer, P., Mösinger, E., and Métraux, J.P. (1998). Heat-induced resistance in barley to powdery mildew (Blumeria graminis f.sp. hordei) is associated with a burst of active oxygen species. Physiological and Molecular Plant Pathology52 : 185-199.

Widiastuti, A., Yoshino, M., Hasegawa, M., Nitta, Y., and Sato, T. (2013). Heat shock-induced resistance increases chitinase-1 gene expression and stimulates salicylic acid production in melon (Cucumis melo L.). Physiological and molecular plant pathology $82: 51-55$.

Xu, Y.P., Lv, L.H., Xu, Y.J., Yang, J., Cao, J.Y., and Cai, X.Z. (2018). Leaf stage-associated resistance is correlated with phytohormones in a pathosystem-dependent manner. Journal of Integrative Plant Biology 60 : 703-722.

Yang, X., Zhu, W., Zhang, H., Liu, N., and Tian, S. (2016). Heat shock factors in tomatoes: Genomewide identification, phylogenetic analysis and expression profiling under development and heat stress. PeerJ 2016 .

Yeh, C.-H., Kaplinsky, N.J., Hu, C., and Charng, Y. (2012). Some like it hot, some like it warm: phenotyping to explore thermotolerance diversity. Plant Science 195 : 10-23.

Yu, J., Cheng, Y., Feng, K., Ruan, M., Ye, Q., Wang, R., Li, Z., Zhou, G., Yao, Z., Yang, Y., and Wan, H. (2016). Genome-wide identification and expression profiling of tomato Hsp20 gene family in response to biotic and abiotic stresses. Frontiers in Plant Science7 : 1-14.

Zhang, H. and Sonnewald, U. (2017). Differences and commonalities of plant responses to single and combined stresses. Plant Journal 90 : 839-855.

Zhou, F., Emonet, A., Dénervaud Tendon, V., Marhavy, P., Wu, D., Lahaye, T., and Geldner, N. (2020). Co-incidence of Damage and Microbial Patterns Controls Localized Immune Responses in Roots. 
Cell180 : 440-453.e18.

Zhu, Y., Qian, W., and Hua, J. (2010). Temperature Modulates Plant Defense Responses Through NB-LRR Proteins. PLoS pathogens6 .

Hosted file

RZW figs 9-9-20 vsn2.docx available at https://authorea.com/users/359213/articles/481380root-zone-warming-represses-foliar-diseases-in-tomato-by-inducing-systemic-immunity 